\title{
The Clinical Implications of Simultaneous Bilateral Chronic Ear Surgery for Patients with Asymmetric Hearing
}

\author{
Sang-Yoon Han ${ }^{1,2}$, Jeong-Yeon Ji ${ }^{1}$, Ye Ji Shim ${ }^{1,3}$, and Min-Hyun Park ${ }^{1,2}$ (D) \\ ${ }^{1}$ Department of Otorhinolaryngology-Head and Neck Surgery, Seoul National University College of Medicine, Seoul; and \\ ${ }^{2}$ Department of Otorhinolaryngology, Boramae Medical Center, Seoul Metropolitan Government-Seoul National University, Seoul; and \\ ${ }^{3}$ Department of Otorhinolaryngology-Head and Neck Surgery, Seoul National University, Hospital Healthcare System Gangnam Center, \\ Seoul, Korea
}

비대칭성 난청환자에서 양측 동시 중이염 수술의 임상적 유용성

한상윤 ${ }^{1,2} \cdot$ 지정연 ${ }^{1} \cdot$ 심예지 ${ }^{1,3} \cdot$ 박민현,2

서울대학교 의과대학 이비인후과학교실, ${ }^{1}$ 서울대학교 보라매병원 이비인후과, ${ }^{2}$ 서울대학교 강남센터 이비인후과 ${ }^{3}$

Received June 18, 2019

Revised September 17, 2019

Accepted October 1, 2019

Address for correspondence

Min-Hyun Park, MD, PhD

Department of Otolaryngology-

Head and Neck Surgery,

Seoul National University

College of Medicine,

20 Boramae-ro 5-gil, Dongjak-gu,

Seoul 07061, Korea

Tel $+82-2-870-2443$

Fax $+82-2-870-3863$

E-mail drpark@snu.ac.kr
Background and Objectives Surgery for bilateral chronic otitis media (COM) is usually performed sequentially, not simultaneously. The main reason is to prevent iatrogenic bilateral conductive hearing loss during recovery period. However, with asymmetric hearing loss, the difference in patient inconvenience between sequential and simultaneous surgery may be the same. This study evaluates the efficacy of simultaneous COM surgery in patients with asymmetric hearing.

Subjects Materials and Method From 2012 to 2018, 9 patients underwent simultaneous bilateral COM surgery. The period of patients' hospital stay, the success rate of tympanoplasty, tolerability for operation, and hearing thresholds were analyzed statistically.

Results For the 8 same-day surgery patients, the mean hospital period was $4.4 \pm 0.7$ days, which was much shorter than that of sequential surgery ( 8 days). Tympanoplasty was successful in all patients without complications. In the better side, the preoperative/postoperative mean air conduction thresholds (AC) were $62.97 \pm 12.89 \mathrm{~dB} / 47.81 \pm 19.07 \mathrm{~dB}(p=0.017)$, the bone conduction thresholds $(\mathrm{BC})$ were $46.72 \pm 10.31 \mathrm{~dB} / 37.66 \pm 16.99 \mathrm{~dB}(p=0.161)$ and the air-bone gaps (ABG) were $16.25 \pm 8.81 \mathrm{~dB} / 10.16 \pm 7.78 \mathrm{~dB}(p=0.176)$. In the worse side, the preoperative/ postoperative mean $\mathrm{AC}$ were $86.56 \pm 18.22 \mathrm{~dB} / 72.18 \pm 29.43 \mathrm{~dB}(p=0.035)$, BC were $53.28 \pm$ $11.10 \mathrm{~dB} / 48.13 \pm 18.41 \mathrm{~dB}(p=0.173)$, and ABG were $33.28 \pm 11.22 \mathrm{~dB} / 24.06 \pm 14.80 \mathrm{~dB}(p=0.500)$. In both ear, the postoperative $\mathrm{AC}$ and $\mathrm{BC}$ were better than or equivocal to those of the preoperative value, and the result was similar with each of the unilateral ear audiological results.

Conclusion Despite the fact that there is no complete consensus to date, simultaneous bilateral COM surgery can be an option when patients have asymmetric hearing loss. Simultaneous bilateral COM surgery could save time, cost, and lead to similar results with sequential surgery, so it could be a considerable surgical option for patients with bilateral COM.

Korean J Otorhinolaryngol-Head Neck Surg 2020;63(2):64-70

Key Words Bilateral hearing loss · Otitis media · Otologic surgical procedure.

This is an Open Access article distributed under the terms of the Creative Commons Attribution Non-Commercial License (https:/creativecommons.org/licenses/by-nc/4.0) which permits unrestricted non-commercial use, distribution, and reproduction in any medium, provided the original work is properly cited. 


\section{서 론}

만성 중이염은, 완치를 위해서는 수술적인 치료가 필수적인 질병이다. 만성 중이염은 20 세 이상의 성인 $3.8 \%$ 에서 발생하는 매우 흔한 질환으로, ${ }^{1)}$ 이 중 약 $15 \%$ 는 양측 만성 중이염 환자 이다. ${ }^{2}$ 양측 만성 중이염 환자에서 수술적 치료를 시행할 때 는 한쪽을 먼저 수술을 시행하고 3 개월 이상의 회복기를 가 진 후에 반대쪽을 수술하는 것이 일반적이다. 양측 동시 중이 염 수술을(simultaneous bilateral chronic otitis media surgery) 시행하지 않는 데는 몇 가지 이유가 있다. 일반적으로 양 측 중이염 수술을 시행하지 않는 가장 큰 이유는 의인성 양측 청력 손실을 막기 위함이며,3-39) 환자의 통증 및 수술 후 패킹 에 의한 일시적인 양측 청력 저하 등도 양측 중이염 수술을 시 행하지 않는 이유이다.1,3,4) 그러나 양측 중이염 수술의 유용성 에 대한 몇몇 연구가 진행되었는데 이 연구들에 따르면 양측 중이염 수술은 술 후 청력적인 측면에서 보면 안전하며, ${ }^{1,3-9)}$ 시 간과 비용, 전신마취 횟수를 줄일 수 있었다.,3-7) 모든 양측 만 성 중이염 환자가 양측 동시 수술의 대상이 되는 것은 위에 언 급한 문제들 때문에 이득이 별로 없다. 하지만 특정 조건을 가 진 환자에서는 양측 중이염 수술이 환자에게 도움이 될 수 있는데, 수술이 필요한 유일청이(only hearing ear)나 혹은 양 측 전농인 경우가 이 대상이 될 수 있다. 일반적으로 유일청이 는 이를 수술함에 있어, 질병의 진행 양상과 추후 더 큰 청각적 결손을 남길 수 있을지에 따라 수술 여부를 결정하게 된다. ${ }^{10}$ 이와 마찬가지로, 양측 만성 중이염 환자에서 보다 나쁜 청력 을 가진 측의 수술 후 기대 청력이, 보다 좋은 청력을 가진 쪽 의 수술 전 기도 청력에 미치지 않는 경우는 유일청이의 수술 을 결정하는 것과 같은 이유로 염증이나 진주종의 진행 상태 에 따라 양측을 동시에 수술을 하는 것을 고려할 수 있다. 따 라서 본 연구에서는, 양측 만성 중이염 환자 중 한쪽이 고도 이상인 비대칭성 난청 환자(asymmetric hearing loss bilateral chronic otitis media patient)를 대상으로 양측 중이염 수술의 결과 및 효과에 대해 분석해 보고자 한다.

\section{대상 및 방법}

2012 2018년까지 본 병원을 내원한 환자 중, 양측 만성 중이 염이 있으며 일측이 고도에 가깝거나, 고도 이상인 비대칭성 난 청을 가진 환자를 대상으로 양측 수술을 받은 9 명의 환자를 대 상으로 후향적 조사를 시행하였다(기관 IRB No. 30-201956-063). 해당 기간 동안 증상, 병의 특성, 귀에 대한 치료력, 과거 병력 등을 포함한 병력을 얻었다. 또한 이경 및 이내시경 을 통한 고막 소견, Valsalva 검사를 통한 이관 기능 평가 결과,
수술 전후 청력도에 대한 자료를 수집하였다. 순음 청력 검사 는 모든 환자군에서 동일하게 시행되었으며 $250,500 \mathrm{~Hz}, 1,2$, $3,8 \mathrm{kHz}$ 의 청력 역치에 대한 결과값을 얻었다. 이후 평균 청력 역치는 $500 \mathrm{~Hz}, 1,2,3 \mathrm{kHz}$ 의 역치값의 평균을 구하여 정의하 였다. 평균 청력을 구하는 과정에서, 청력이 계측불가(scaleout)인 경우, 기계가 측정 가능한 수치의 한계값을 이용하여 계산하였다. 모든 환자에서 병변의 정도와 양상을 보기 위해 수술 전 측두골 컴퓨터단층촬영(temporal bone $\mathrm{CT}$ )을 시행 하였다.

\section{포함 기준(Inclusion criteria)}

양측 중이염 수술에 대한 대상군을 아래와 같은 포함 기준 을 사용하여 선별하였다: 1) 만 18세 이상의 환자, 2) 양측 중 이염을 않고 있는 환자, 3) 진주종성 중이염이 아닌 환자, 4) 양 측 중이염 수술에 대해 고지된 동의를 받은 경우, 5) 비대칭적 청력을 가지면서 일측이 고도 이상의 난청인 경우 혹은 보다 나쁜 측의 수술 후 기대 청력이, 보다 좋은 측의 수술 전 청력 역치를 넘지 못할 것으로 예상되는 경우.

\section{환자의 인구학적 특징}

최종적으로 9명의 환자(남자:여자=6:3, 평균 연령 $59.2 \pm$ 5.8)가 2012 2018년 사이에 양측 중이염 수술을 시행받았다. 이 중 한 환자는 우측 추체아전절제술 및 인공와우 수술을 시 행한 후 1 주 후 좌측 중이염 수술을 시행하였다. 일반적으로 연속적 수술(sequential surgery)은 회복기를 가진 이후에 시 행하는 것을 지칭하는 것이며 이 환자는 동시에 시행한 것은 아니지만 수술적 위험 및 청력 측면에서는 동시 수술과 같은 점을 가지고 있어서 연구에 포함하였다. 수술 전 청력 재활은, 연구에 포함된 환자들 중 두 명이 보청기를 사용하고 있었으 며, 다른 환자들은 수술 전 보청기를 사용하지 않았다.

\section{자료 추출, 통계 분석}

환자군의 재원 기간, 고막 이식물 안착 여부 및 고실성형술 의 성공률, 고통의 숫자등급척도(Numerical Rating Scale, $\mathrm{NRS)}$, 청각학적 결과를 의무기록을 통해 후향적으로 모았다. 모든 환자군에서 수술 전, 후 기도 및 골도청력검사를 시행하 였다. 수술 전후 청력에 대해서는 Wilcoxon signed rank test 를 통하여 분석하였다.

\section{결 과}

환자의 시간, 비용, 고통 감내력

양이를 하루에 수술한 환자 8명의(우측 추체아전절제술 및 
인공와우 수술 후 좌측 중이염 수술을 한 환자 1명 제외) 평균

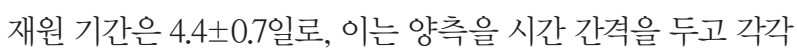
따로 수술했을 때의 재원 기간보다(8일) 횔씬 짧은 기간이었 다. 또한 재원 기간의 감소에 따른 입원 비용도 감소하였다. 모 든 고막 이식물은 이상 없이 이식이 되었고, 수술 직후 재천 공이나 감염 등은 발생하지 않았다. 평균적인 수술 1 일 후 통 증 점수는 숫자등급척도로(NRS) $2.6 \pm 1.4$ 이었다.

\section{이식 성공률 및 수술 후 합병증}

수술은 고실성형술뿐만 아니라, 공동폐쇄 유양동절제술, 공동개방 유양동절제술을 시행한 경우를 모두 포함하였으며, 각 동시 수술의 수술명은 Table 1에 정리하였다. 수술 후 평균 적인 경과 관찰 기간은 $23.10 \pm 28.61$ 개월로, 모든 환자군에서 수술 후 시행한 고막검진에서 천공이나 혹은 이루는 없었다 (Fig. 1). 그러나 한 환자에서는 77개월 이후 발견된 나쁜 청력 을 가진 일측 귀의 이루 및 천공, 중이염 재발 소견으로 재수
술을 시행하였다. 또한 모든 수술은 전신마취하에 진행되었으 며, 마취의 중대한 합병증은 없었다.

\section{청각학적 결과}

수술 후 청력검사를 시행한 8명의 환자를 대상으로(인공와 우 시행한 환자 제외) 청력 호전 및 손실에 대하여 통계학적인 분석을 시행하였다. 평균적인 수술 후 청각검사까지 경과 관찰 기간은 $17.88 \pm 23.94$ 개월로 각 환자들에게 기도 청력, 골도 청 력을 각각의 귀에 대해 측정하였고, 모든 환자에서 청력이 좋 은 측 귀와 청력이 좋지 않은 측의 귀 모두 수술 후의 청력이 수술 전보다 좋거나 혹은 수술 전과 유사하게 유지되는 양상 을 보였다(Table 2). 청력이 좋은 측의 경우, 수술 전/후의 기도 청력은 $62.97 \pm 12.89 / 47.81 \pm 19.07 \mathrm{~dB}(p=0.017)$ 로 통계적으 로 유의하게 호전되었음을 보였으며, 골도 청력은 46.72 \pm 10.31 / $37.66 \pm 16.99 \mathrm{~dB}(p=0.161)$ 로 통계적으로 유의한 차이를 보이 지 않았다. 기도-골도 역치 차는 $16.25 \pm 8.81 / 10.16 \pm 7.78 \mathrm{~dB}$

Table 1. Operation name, use of hearing aids, types of chronic otitis media

\begin{tabular}{|c|c|c|c|c|}
\hline \multirow{2}{*}{ Case } & \multicolumn{2}{|c|}{ Better side } & \multicolumn{2}{|c|}{ Worse side } \\
\hline & Operation name & Use of $\mathrm{H}$-aid & Operation name & Use of $\mathrm{H}$-aid \\
\hline A & Mastoidotomy w T1 & Use & Mastoidotomy w T1 & Use \\
\hline B & ICW $\mathrm{W} T \mathrm{Tl}$ & Use & CD w PORP & Non-use \\
\hline C & $\begin{array}{l}\text { Subtotal petrosectomy with } \\
\qquad \mathrm{Cl}\end{array}$ & Non-use & Mastoidotomy w Tl & Non-use \\
\hline $\mathrm{D}$ & Mastoidotomy w Tl & Non-use & Mastoidotomy w PORP & Non-use \\
\hline$E$ & ICW W TI & Non-use & Mastoidotomy w T1 & Non-use \\
\hline $\mathrm{F}$ & Mastoidotomy w Tl & Non-use & Mastoidotomy w T1 & Non-use \\
\hline G & Mastoidotomy w Tl & Non-use & revision CD w TO & Non-use \\
\hline $\mathrm{H}$ & Mastoidotomy w Tl & Non-use & Mastoidotomy w T1 & Non-use \\
\hline I & Mastoidotomy w T1 & Non-use & Mastoidotomy w T1 & Non-use \\
\hline
\end{tabular}

ICW: intact canal wall mastoidectomy, w: with, CD: canal wall down mastoidectomy, PORP: partial ossicular replacement prosthesis, TO: tympanization, T1: tympanoplasty type 1, H-aid: hearing aid, Cl: cochleair implantation
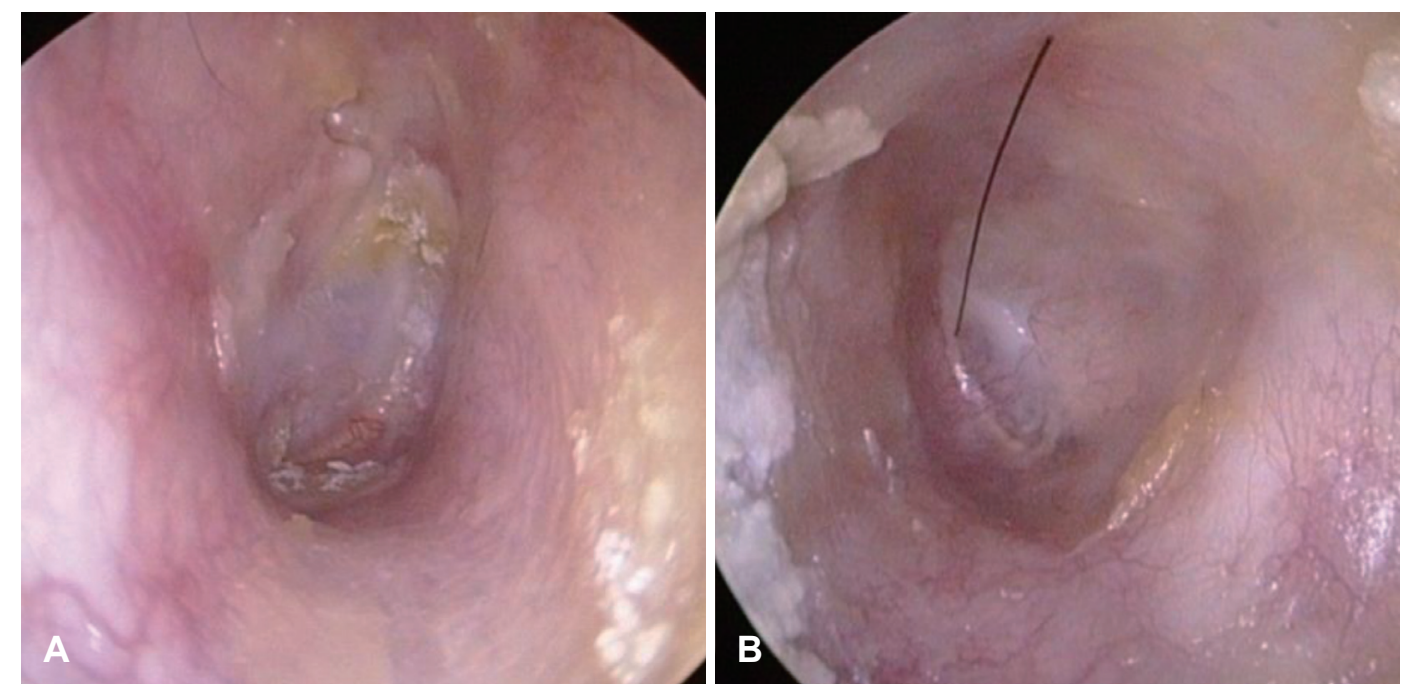

Fig. 1. Postoperative right (A) and left (B) well healed tympanic membrane findings of one patient. 
$(p=0.176)$ 로, 수술 후의 역치 차 값의 평균이 적으나, 통계적으 로 유의한 차이는 보이지 않았다(Fig. 2). 각각을 살펴보면, 기 도-골도 역치 차가 $20 \mathrm{~dB}$ 이상 호전 1 명, $10 \mathrm{~dB}$ 이상 $20 \mathrm{~dB}$ 미만 호전 2명, $10 \mathrm{~dB}$ 미만 3명이었고 2명은 기도-골도 역치 차가 증가하였다. 기도-골도 역치 차가 증가한 두 명은 모두 기도/골도 청력이 좋아졌으나, 골도 청력의 호전 폭이 컸다. 청 력이 안 좋은 측의 수술 전/후 기도 청력은 86.56 $18.22 \mathrm{~dB} /$ $72.18 \pm 29.43 \mathrm{~dB}(p=0.035)$ 이었으며, 통계적으로 유의하게 청
력이 호전되었고, 골도 청력은 수술 전/후 $53.28 \pm 11.10 \mathrm{~dB} /$ $48.13 \pm 18.41 \mathrm{~dB}(p=0.173)$ 로 유의미한 차이를 보이지 않았다. 기도-골도 역치차는 $33.28 \pm 11.22 \mathrm{~dB} / 24.06 \pm 14.80 \mathrm{~dB}(p=$ 0.500)로 통계적으로 유의미한 차이를 보이지 않았다(Fig. 3). 각각을 살펴보면, 기도-골도 역치 차가 $20 \mathrm{~dB}$ 이상 호전 1명, $10 \mathrm{~dB}$ 이상 $20 \mathrm{~dB}$ 미만 호전 4명, $10 \mathrm{~dB}$ 미만 1명이었고 2명 은 기도-골도 역치 차가 증가하였다. 기도-골도 역치 차가 증 가한 두 명 중 한 명은, 양측 전농인 환자였으며, 다른 한 명은

Table 2. Preoperative and postoperative audiometry results of nine bilateral chronic otitis media surgery undergone patients

\begin{tabular}{|c|c|c|c|c|c|c|}
\hline \multirow[b]{2}{*}{ Case } & \multicolumn{3}{|c|}{ Better side } & \multicolumn{3}{|c|}{ Worse side } \\
\hline & $\begin{array}{c}\text { Pre/Post AC } \\
(\mathrm{dB})\end{array}$ & $\begin{array}{c}\text { Pre/Post BC } \\
(\mathrm{dB})\end{array}$ & $\begin{array}{c}\text { Pre/Post ABG } \\
(\mathrm{dB})\end{array}$ & $\begin{array}{c}\text { Pre/Post AC } \\
(\mathrm{dB})\end{array}$ & $\begin{array}{c}\text { Pre/Post BC } \\
(\mathrm{dB})\end{array}$ & $\begin{array}{c}\text { Pre/Post ABG } \\
(\mathrm{dB})\end{array}$ \\
\hline A & $68.75 / 51.25$ & $35.00 / 47.50$ & $33.75 / 3.75$ & $110.00 / 118.75$ & $67.50 / 67.50$ & $42.50 / 51.25$ \\
\hline B & $52.50 / 53.75$ & $37.50 / 38.75$ & $15.00 / 15.00$ & $76.25 / 83.75$ & $51.25 / 55.00$ & $25.00 / 28.75$ \\
\hline C & $118.75 /-$ & $67.50 /-$ & $-1-$ & $118.80 /-$ & $67.50 /-$ & $-/-$ \\
\hline D & $46.25 / 13.75$ & $40.00 / 13.75$ & $6.25 / 0.00$ & $106.25 / 95.00$ & $37.50 / 21.25$ & $45.00 / 13.75$ \\
\hline$E$ & $78.75 / 75.00$ & $60.00 / 52.50$ & $18.75 / 22.50$ & $87.50 / 65.00$ & $62.50 / 63.75$ & $43.75 / 31.25$ \\
\hline $\mathrm{F}$ & $80.00 / 60.00$ & $62.50 / 53.75$ & $17.50 / 6.25$ & $101.25 / 90.00$ & $60.00 / 53.75$ & $27.50 / 11.25$ \\
\hline G & $68.75 / 56.25$ & $51.25 / 52.50$ & $17.50 / 17.50$ & $58.75 / 47.50$ & $61.25 / 60.00$ & $40.00 / 30.00$ \\
\hline $\mathrm{H}$ & $51.25 / 43.75$ & $46.25 / 28.75$ & $5.00 / 15.00$ & $70.00 / 42.50$ & $45.00 / 43.75$ & $13.75 / 3.75$ \\
\hline I & $57.50 / 28.75$ & $41.25 / 13.75$ & $16.25 / 10.16$ & $106.25 / 95.00$ & $41.25 / 20.00$ & $28.75 / 22.50$ \\
\hline Mean* & $62.90 / 47.81$ & $46.72 / 37.66$ & $16.25 / 10.16$ & $86.56 / 72.19$ & $53.28 / 48.13$ & $33.28 / 24.06$ \\
\hline SD* & 12.89/19.07 & $10.31 / 16.99$ & $8.81 / 7.78$ & $18.22 / 29.43$ & $11.10 / 18.41$ & $11.22 / 14.80$ \\
\hline
\end{tabular}

*except for $\mathrm{Cl}$ patient. Pre: preoperative, Post: postoperative, AC: air conduction audiogram, BC: bone conduction audiogram, SD: standard deviation, ABG: aided audiogram, Cl: cochleair implantation

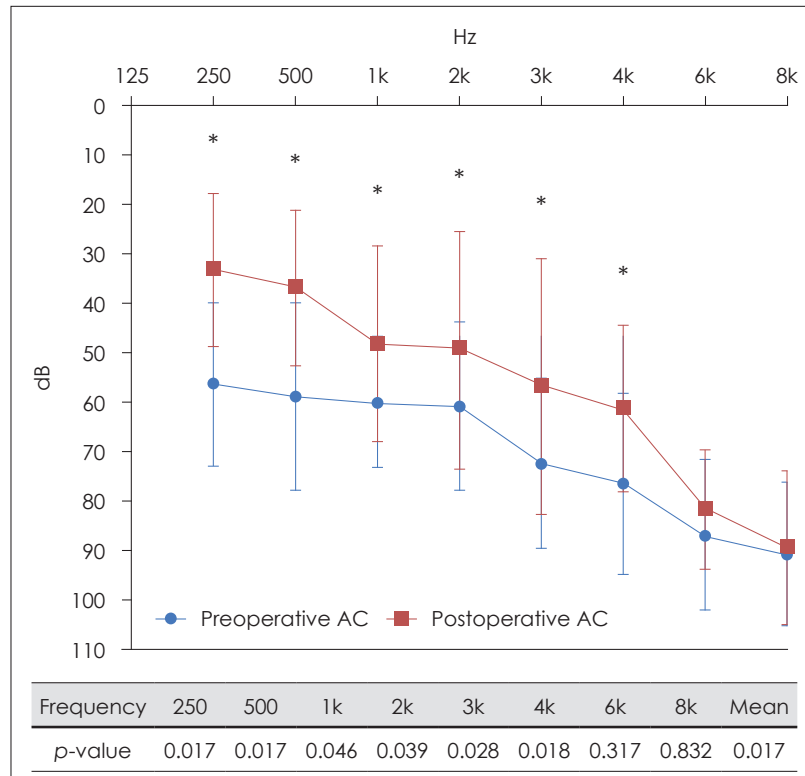

A

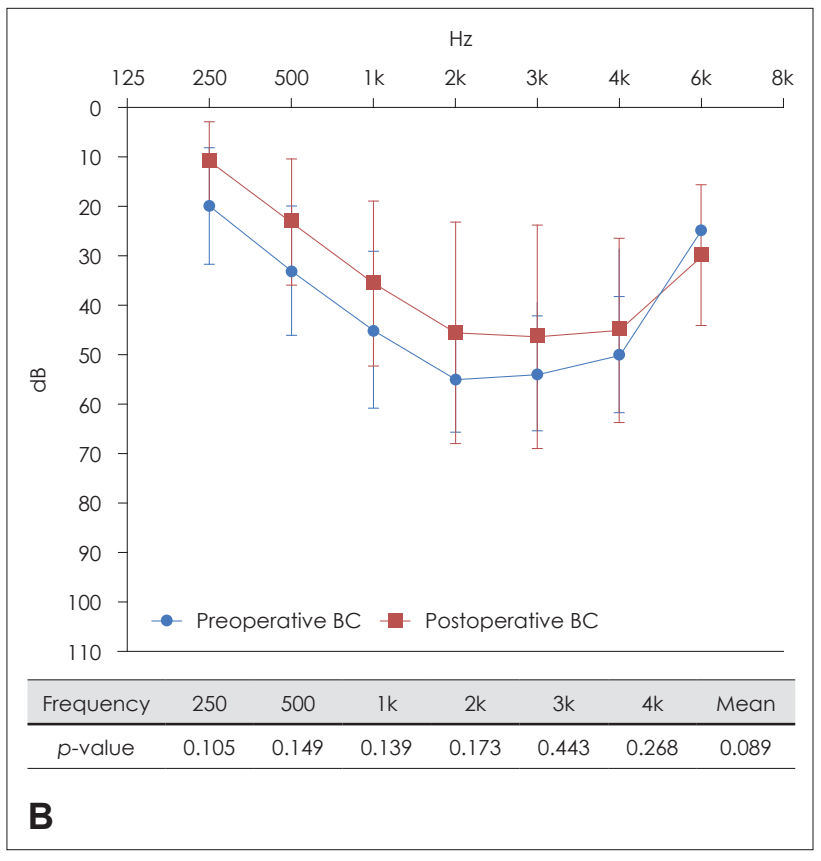

Fig. 2. Better side mean preoperative and postoperative $A C$ of bilateral COM patients. The mean postoperative air conduction of each frequency was better than the mean preoperative in all frequency and it was statistically meaningful in frequency of $250,500 \mathrm{~Hz}, 1,2,3$, $4 \mathrm{kHz}$, and mean value (A). Better side mean preoperative and postoperative BC of bilateral COM patients. The mean postoperative bone conduction was equivocal to the mean preoperative bone conduction in all frequency (B). *statstically meaningful difference between preoperative $\mathrm{AC}$ and postoperative $\mathrm{AC}(p<0.05)$. AC: air conduction audiogram, BC: bone conduction audiogram, COM: chronic otitis media. 


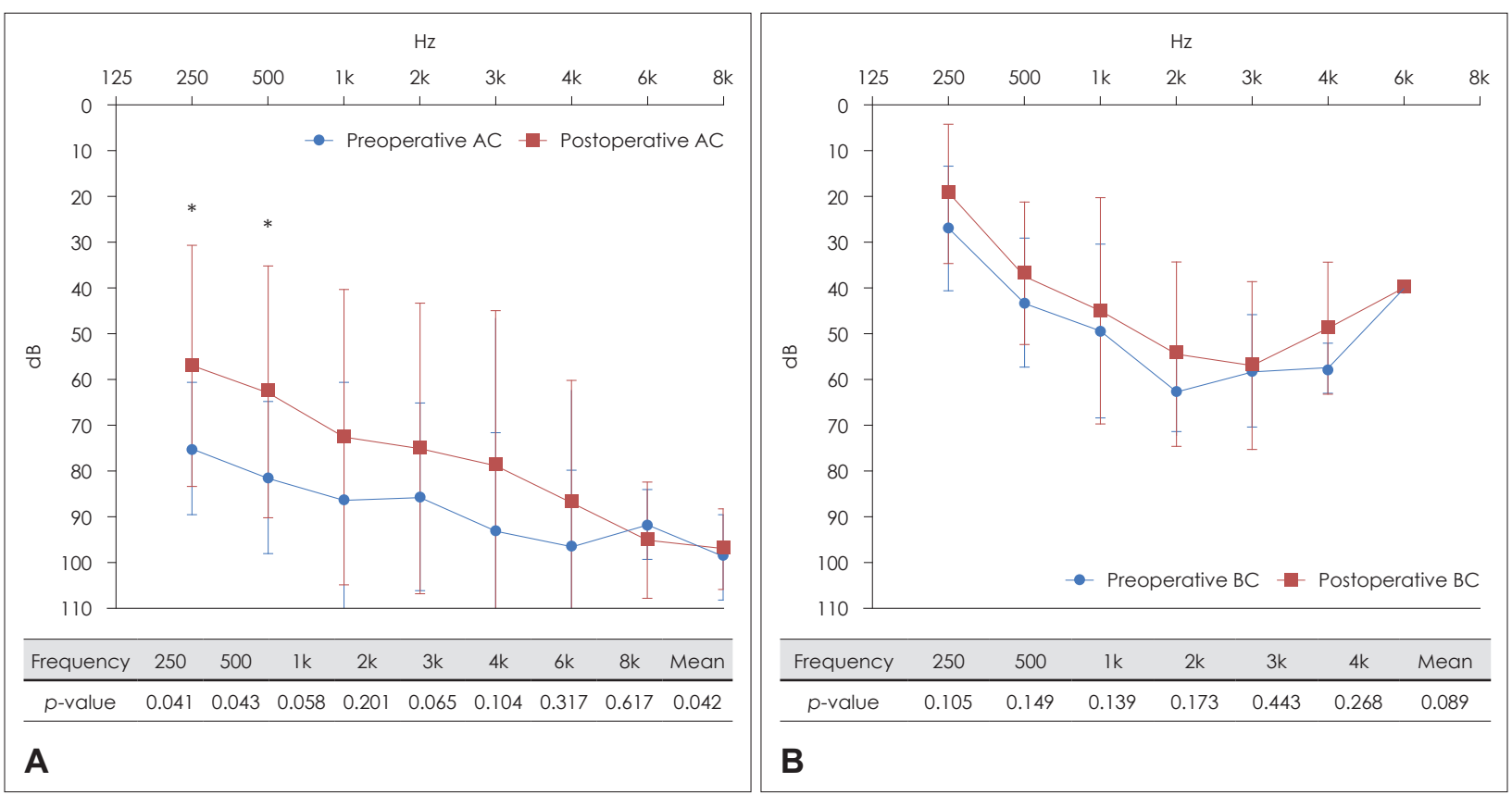

Fig. 3. Worse side mean preoperative and postoperative $A C$ of bilateral COM patients. The mean postoperative air conduction of each frequency was better than the mean preoperative air conduction except for $6 \mathrm{kHz}$ and it was statistically meaningful in frequency of 250 , $500 \mathrm{~Hz}$, and mean value (A). Worse side mean preoperative and postoperative BC of bilateral COM patients. The mean postoperative bone conduction was equivocal to the mean preoperative bone conduction in all frequency $(B)$. *statstically meaningful difference between preoperative $\mathrm{AC}$ and postoperative $\mathrm{AC}(p<0.05)$. AC: air conduction audiogram, BC: bone conduction audiogram, COM: chronic otitis media.

$3.25 \mathrm{~dB}$ (수술 전: $25 \mathrm{~dB}$, 수술 후: $28.25 \mathrm{~dB}$ )이 증가하였다.

\section{고 찰}

양측 동시 중이 수술을 시행하는 것은 현재도 논란이 많으 나, 일부 선별된 환자군에 대하여 매우 조심스럽게 시행되고 있다. 많은 논문에서 양측 동시 중이 수술에 대한 내용을 다 루고 있으나, 이에 대하여 각기 다른 적응증을 적용하고 있었 다. ${ }^{3-5)}$ 각 연구자들은 각자의 기준을 가지고 환자군을 선별해 양측 중이염 수술을 시행해왔다. Caye-Thomasen 등는 마르 고 육아조직이 적은 경우, 양측 고막성형술이나 제1형 고실성 형술을 시행하는 연구를 하였고, 이 수술이 안전하고 비용 효 율적이라는 결론을 내렸다. 그들은 양측의 육아조직이 많은 경우, 의인성 청력 감소가 발생할 수 있어 육아조직이 없는 경 우의 시행을 권고하였으며, 이소골성형술을 시행할 필요가 적 은 환자에서만 권고하였다. Rai 등은 진주종, 육아조직이 없 고, 처음 수술하는 환자이며, 유일청이가 아닌 경우, 난청 정 도가 심하지 않은 경우에만 수술하였다. Homøe 등은 의료 시설에 대한 접근이 용이하지 않은 환자들을 대상으로 연구 를 진행하였으며, 이 경우 양측을 동시에 하는 것이 비용과 시 간을 상당히 줄여주어서 양측 동시 수술이 유리할 수 있다는 결론을 내렸다. 이외에 몇몇 연구들은 양측 고실성형술 및 양 측 고막성형술의 결과에 대해 분석하였으며, $3,4,6,7,7,11)$ 몇몇의
연구들은 양측 유양동 절제술에 대해 연구를 진행하였다. ${ }^{1,8)}$ 이 연구들은 양측 동시 중이염 수술이 안전하고 효율적일 수 있으며, 심각한 의인성 청력 손실을 유발하지 않는다는 결론 을 내렸다. 양측 고실성형술의 의인성 청력손실 이외의 합병증 에 대하여 Mane 등 ${ }^{11}$ 과 Ranghuwanshi와 Asati ${ }^{7}$ 는 수술 직 후 패킹으로 인한 양측 귀의 전도성 난청이 생기는 일시적 불 편감에 대해 논하였으나, 대부분 1 주 후 젤폼 패킹을 제거한 후 호전되어 크게 문제가 되지 않는다는 결론을 내렸다. Kim 드이 은 또한 양측 고삭신경의 일시적, 영구적 손상으로 이에 대한 미각 손실이 있을 수 있다는 점을 제시하였으나, 영구적으로 양측 손상이 생기는 경우는 드물다는 결론을 내렸다. 이처럼, 대부분의 연구에서 높은 고막 이식 성공률과 청력 개선을 보 였고, 중대한 합병증은 유발하지 않았다(Table 3). 이는 본 연 구의 결과와도 부합하는 소견으로, Table 3의 요약된 결과에 서 보듯 양측 동시 중이염 수술은 좋은 청각학적 결과와 이식 성공률을 보인다.

심지어 일부 연구자들은 양측 전도성 난청에 대하여 양이 수술을 동시에 진행하기도 하였다. Kujala 등 ${ }^{12,13)}$ 은 양측 등 골 수술을 동시에 진행하는 연구를 진행하였고, 이들이 충분 히 안전할 수 있다는 결론을 내렸다. 대부분의 양측 중이염 수술에 대한 연구들은 양측 중이염 수술이 양측 의인성 감각 신경성 난청을 일으킬 확률이 낮으면서도, 환자의 비용, 시간 (총 재원 기간, 수술 후 상처 관리를 위한 내원 기간)을 절약 
할 수 있게 해준다는 결론을 내리고 있다. 그러나 양측 의인 성 청력 저하의 위험은 항상 존재할 수밖에 없으므로, ${ }^{14-16)}$ 양 측 중이염 수술을 결정하기 위한 청각학적 기준은 필요하다.

이 연구에서는, 양측 중이염을 가진 환자 중 비대칭적으로 고도 이상의 난청을 가진 경우를 선택 기준의 하나로 삼았다. 만일 일측의 질환이 활동성 중이염이나 진주종과 같은 진행 하는 질환인 경우이면서 편측이 고도 이상의 난청인 경우 편 측의 청력과 관계없이 중이염 수술은 시행되어야 한다. 많은 연구자들로부터 이와 같은 유일청이를 수술하는 경우, 안전하 게 수술될 수 있음에 대하여 이미 연구가 진행되었다. ${ }^{10,17,18)}$ 유
일청이의 수술을 결정하는 것과 마찬가지로, 만일 환자가 유 일청이에 가까운 비대칭적 청력을 가지고 있으면서 진행성 중 이염이나 진주종을 가지고 있는 경우, 청력이 좋은 측의 귀를 수술하는 것은 청력이 나쁜 측의 수술 결과와 관계없이 시행 여부를 결정할 수 있다. 그러므로, 비대칭성 고도 이상의 난청 이 있는 양측 중이염 환자의 경우, 양측 동시 중이염 수술을 할 수 있는 적응증이 될 수 있다.

이 연구에서는, 적은 환자군을 대상으로 할 수 밖에 없었는 데 이는 양측 중이염 환자에서 위와 같은 적응증에 해당하 는 환자가 많지 않았기 때문이다. 또한, 이 연구에서는, 비교할

Table 3. Studies for simultaneous bilateral ear surgery

\begin{tabular}{|c|c|c|c|c|c|}
\hline Study & Disease & No. & $\begin{array}{l}\text { Operation method } \\
\text { and analysis }\end{array}$ & Main parameter & Results \\
\hline Kim et al. ${ }^{\prime \prime}$ & $\begin{array}{l}\text { COM w or } \\
\text { w/o chole }\end{array}$ & $\begin{array}{l}176 \text { ears } \\
85 \text { pts }\end{array}$ & $\begin{array}{l}\text { Compare } \\
\text { mastoidectomy } \\
\text { with tympanoplasty }\end{array}$ & $\begin{array}{l}\text { 1) Audiologic gain } \\
\text { (ABG } \leq 20 \mathrm{~dB} \text { ) } \\
\text { 2) Permanent taste } \\
\text { change } \\
\text { 3) Re-perforation } \\
\text { (at least one side) }\end{array}$ & $\begin{array}{l}\text { 65.63\% of mastoidectomy side } \\
71.25 \% \text { of tympanoplasty side } \\
1.56 \% \text { of surgery with mastoidectomy } \\
\text { (at least one side) } \\
0.00 \% \text { of bilateral tympanoplasty } \\
6.25 \% \text { of surgery with mastoidectomy } \\
\text { (at least one side) } \\
12.5 \% \text { of bilateral tympanoplasty }\end{array}$ \\
\hline Rai et al. ${ }^{3)}$ & $\begin{array}{l}\text { COM w/o } \\
\text { chole }\end{array}$ & 60 pts & $\begin{array}{l}\text { Compare bilateral } \\
\text { type I tympanoplasty } \\
\text { with unilateral }\end{array}$ & $\begin{array}{l}\text { 1) Graft success rate } \\
\text { 2) Audiologic gain } \\
\text { 3) latrogenic SSNHL }\end{array}$ & $\begin{array}{l}93 \% \text { of bilateral ear surgery (comparable } \\
\text { graft success rate to unilateral: } 90 \% \text { ) } \\
94 \% \text { of bilateral ear surgery (comparable } \\
\text { graft success rate to unilateral: } 94 \% \text { ) } \\
\text { No iatrogenic SSNHL in unilateral and } \\
\text { bilateral operation group }\end{array}$ \\
\hline $\begin{array}{l}\text { Caye-Thomasen } \\
\text { et al. }{ }^{4 l}\end{array}$ & $\begin{array}{l}\text { COM w/o } \\
\text { chole }\end{array}$ & $\begin{array}{l}52 \text { ears } \\
26 \text { płs }\end{array}$ & $\begin{array}{l}\text { Myringoplasty and } \\
\text { type I tympanoplasty }\end{array}$ & $\begin{array}{l}\text { 1) Graft success rate } \\
\text { 2) Audiologic gain }\end{array}$ & $\begin{array}{l}94 \% \text { of ears, } 88 \% \text { of patients } \\
92 \% \text { of the ear, } 88 \% \text { of patients }\end{array}$ \\
\hline Homøe et al. ${ }^{5}$ & $\begin{array}{l}\text { COM w/o } \\
\text { chole }\end{array}$ & 17 pts & $\begin{array}{l}\text { Myringoplasty and } \\
\text { type I tympanoplasty }\end{array}$ & $\begin{array}{l}\text { 1) Graft success rate } \\
\text { 2) Audiologic gain } \\
\text { 3) Cholesteatoma }\end{array}$ & $\begin{array}{l}82 \% \text { - at least } 1 \text { graft success } \\
65 \% \text { - bilateral graft success } \\
82 \% \text { - at least one ear hearing gain, PTA } \\
\text { less than } 25 \mathrm{~dB} \text { (right } 18 \mathrm{~dB} \text {, left } 14 \mathrm{~dB} \text { ) } \\
71 \% \text { - satisfied for hearing gain. } \\
\text { Only one pts }\end{array}$ \\
\hline Katsura et al. ${ }^{6)}$ & $\begin{array}{l}\text { COM w/o } \\
\text { chole }\end{array}$ & 200 pts & $\begin{array}{l}\text { Myringoplasty and } \\
\text { type I tympanoplasty }\end{array}$ & $\begin{array}{l}\text { 1) Graft success rate } \\
\text { 2) Audiologic gain }\end{array}$ & $\begin{array}{l}91 \% \text { of myringoplasty }(80 \% \text { - both) } \\
75 \% \text { of tympanoplasty }(67 \% \text { - both) } \\
29 \% \text { less than } 10 \mathrm{~dB} \text { post op } A B G \\
88 \% \text { less than } 20 \mathrm{~dB} \text { post op ABG }\end{array}$ \\
\hline $\begin{array}{l}\text { Raghuwanshi } \\
\text { and Asati }\end{array}$ & $\begin{array}{l}\text { COM w/o } \\
\text { chole }\end{array}$ & $\begin{array}{l}32 \text { pts } \\
64 \text { ears }\end{array}$ & Type I tympanoplasty & $\begin{array}{l}\text { 1) Graft success rate } \\
\text { 2) Audiologic gain }\end{array}$ & $\begin{array}{l}93.75 \% \text { ( } 100 \% \text { - at least one ear success) } \\
93.33 \% \text { (mean hearing gain } 10.8 \mathrm{~dB} \text { ) } \\
70.00 \% \text { - less than } 10 \mathrm{~dB}, 91.6 \% \text { within } 20 \mathrm{~dB}\end{array}$ \\
\hline Klemens et al. $^{8)}$ & $\begin{array}{l}\text { COM w or } \\
\text { w/o chole }\end{array}$ & $\begin{array}{l}12 \text { pts } \\
24 \text { ears }\end{array}$ & $\begin{array}{l}\text { Tympanoplasty w or } \\
\text { w/o mastoidectomy }\end{array}$ & $\begin{array}{l}\text { 1) Audiologic gain } \\
\text { 2) Complications }\end{array}$ & $\begin{array}{l}\text { 87.5\% improved. The others equivocal } \\
12.50 \% \text { of ears with LSCC open and } \\
\text { healed in blind sac, } \\
4.17 \% \text { of ears with FN exposed (extensive } \\
\text { cholesteatoma cases) }\end{array}$ \\
\hline Yu and Yoon" & $\begin{array}{l}\text { COM w/o } \\
\text { chole }\end{array}$ & 81 pts & $\begin{array}{l}\text { Type I tympanoplasty } \\
\text { or myringoplasty }\end{array}$ & $\begin{array}{l}\text { 1) Graft success rate } \\
\text { 2) Audiologic gain }\end{array}$ & $\begin{array}{l}100 \% \\
83 \% \text { of myringoplasty cases } \\
71 \% \text { of tympanoplasty cases }\end{array}$ \\
\hline Mane et al. ${ }^{11)}$ & $\begin{array}{l}\text { COM w/o } \\
\text { chole }\end{array}$ & $\begin{array}{l}14 \text { pts } \\
28 \text { ears }\end{array}$ & Type I tympanoplasty & $\begin{array}{l}\text { 1) Graft success rate } \\
\text { 2) Audiologic gain }\end{array}$ & $\begin{array}{l}96 \% \\
100 \% \text { (mean ABG: } 15.8 \mathrm{~dB} 8.4 \mathrm{~dB} \text { ) }\end{array}$ \\
\hline This study & & 9 pts & $\begin{array}{l}\text { Tymapnopalsty and } \\
\text { mastoidectomy }\end{array}$ & $\begin{array}{l}\text { 1) Graft success rate } \\
\text { 2) Audiologic gain }\end{array}$ & $\begin{array}{l}100.00 \% \\
73.33 \% \text { of both ear, the others equivocal }\end{array}$ \\
\hline
\end{tabular}

No.: the number of cases, pts: patients, COM: chronic otitis media, w/o: without, w: with, chole: cholesteatoma, dB: decibel, POD: postoperative day, PTA: pure tone audiometry, ABG: air-bone conduction gap, SSNHL: sudden sensorineural hearing loss, LSCC: lateral semicircular canal, FN: facial nerve 
만한 대조군을 확보하지 못하였다. 양측 동시 중이염 수술의 유용성에 대한 근거를 위해 추후 보다 많은 환자를 대상으로 한 환자-대조군 연구를 통해 환자의 주관적인 고통 감내력 및 청력 개선의 정도, 수술 후 청력 감소를 일측씩 순차적으로 수술을 진행하는 대조군과 비교하여 유사한 정도를 보이는

지에 대한 확인이 필요하다.

명확히 정해진 적응증은 없지만, 비대칭적으로 고도 이상 의 난청을 가진 환자에서 청력이 나쁜 측의 청력 보존 여부는, 청력이 좋은 귀의 수술 시행 여부를 결정하는 데 있어서 고려 대상이 되지는 않기 때문에, 이 경우에는 양측 중이염 수술을 시도해 볼 수 있다. 양측 중이염 수술은 시간과 비용을 절약해 주면서도, 청력 개선 및 부작용의 측면에 있어서 순차적으로 양이를 수술하는 것과 유사한 수술적 결과를 얻을 수 있어 좋은 적응증이 될 수 있을 것으로 생각한다.

\section{Acknowledgments}

None.

\section{Author Contribution}

Conceptualization: Min-Hyun Park. Data curation: Sang-Yoon Han, Jeong-Yeon Ji. Formal analysis: Sang-Yoon Han, Jeong-Yeon Ji. Investigation: Ye Ji Shim, Min-Hyun Park. Methodology: Min-Hyun Park. Project administration: Min-Hyun Park. Resources: Min-Hyun Park. Supervision: Min-Hyun Park, Ye Ji Shim. Validation: Ye Ji Shim. Visualization: Sang-Yoon Han. Writing — original draft: Sang-Yoon Han. Writing — review \& editing: Ye Ji Shim, Min-Hyun Park.

\section{ORCID}

Min-Hyun Park https://orcid.org/0000-0003-4156-7639

\section{REFERENCES}

1) Kim CW, Lee JS, Park CH, Kwon SY, Kim DK, Lee JH. Comparison of sequential same-day middle ear surgeries: Bilateral mastoidectomy, unilateral mastoidectomy with contralateral tympanoplasty, and bilateral tympanoplasty. Eur Arch Otorhinolaryngol 2015;272(6): 1395-402.
2) Kim J, Park SK, Park JH, Lee DW, Choi YS, Shin SO. Clinical characteristics of bilateral chronic otitis media. Korean J Otorhinolaryngol-Head Neck Surg 2014;57(12):821-5.

3) Rai AK, Singh GB, Sahu R, Singh S, Arora R. Evaluation of simultaneous bilateral same day tympanoplasty type I in chronic suppurative otitis media. Auris Nasus Larynx 2014;41(2):148-52.

4) Caye-Thomasen P, Nielsen TR, Tos M. Bilateral myringoplasty in chronic otitis media. Laryngoscope 2007;117(5):903-6.

5) Homøe P, Sørensen HC, Tos M. Mobile, one stage, bilateral ear surgery for chronic otitis media patients in remote areas. J Laryngol Otol 2009;123(10):1108-13.

6) Katsura H, Sakagami M, Tsuji K, Muto T, Okunaka M, Mishiro Y, et al. Reevaluation of bilateral same-day surgery for bilateral perforated chronic otitis media. Otol Neurotol 2005;26(5):842-5.

7) Raghuwanshi SK, Asati DP. Outcome of single-sitting bilateral type 1 tympanoplasty in Indian patients. Indian J Otolaryngol Head Neck Surg 2013;65(Suppl 3):622-6.

8) Klemens JJ, Mhoon E, Redleaf M. Is simultaneous bilateral mastoidectomy ever advisable? J Laryngol Otol 2007;121(11):1041-7.

9) Yu MS, Yoon TH. Bilateral same-day surgery for bilateral perforated chronic otitis media: Inlay butterfly cartilage myringoplasty. Otolaryngol Head Neck Surg 2010;143(5):669-72.

10) Battaglia AS, Sabri AN, Jackson CG. Management of chronic otitis media in the only hearing ear. Laryngoscope 2002;112(4):681-5.

11) Mane R, Patil B, Mohite A, Varute VV. Bilateral type 1 tympanoplasty in chronic otitis media. Indian J Otolaryngol Head Neck Surg 2013; 65(4):293-7.

12) Kujala J, Aalto H, Ramsay H, Hirvonen T. Simultaneous bilateral stapes surgery--a pilot study. Acta Otolaryngol 2007;127(12):1255-8.

13) Kujala J, Aalto H, Ramsay H, Hirvonen TP. Simultaneous bilateral stapes surgery. Acta Otolaryngol 2008;128(4):347-51.

14) Tos M, Lau T, Plate $S$. Sensorineural hearing loss following chronic ear surgery. Ann Otol Rhinol Laryngol 1984;93(4 Pt 1):403-9.

15) Strauss P. [Hearing results following tympanoplasty (author's transl)]. HNO 1979;27(7):217-20.

16) Smyth GD. Sensorineural hearing loss in chronic ear surgery. Ann Otol Rhinol Laryngol 1977;86(1 Pt 1):3-8.

17) Kalcioglu MT, Cetinkaya Z, Toplu Y, Hanege FM, Kokten N. Chronic otitis media surgery in the only hearing ear. B-ENT 2015; 11(3):223-7.

18) Sanna M, Shea CM, Gamoletti R, Russo A. Surgery of the 'only hearing ear' with chronic ear disease. J Laryngol Otol 1992;106(9): 793-8. 